\title{
JOURNEY OF BIG BERTHA WEBSTER
}

\section{JA Pryse, Oklahoma Historical Society, USA}

Providing material culture through digital transformation of original sound offers societal representation for forthcoming historians to act as archival archaeologists. Shifting paradigmatically as caretakers of physical repositories into dematerialization of antiquated matter offers a new level of fruition through cultural realization of that material.

Through understanding material, accompanying paraphernalia, monetary influence, popular trends, and practical operation of obsolete machinery, the 'archival archaeologist' essentially provides the societal 'unpacking' of cultural moments in time. The Oklahoma Historical Society focuses research on materialization of historical evolution through creation, collection, and preservation, as well as through the dematerialization of each collectively.

For decades, the Society has collected magnetic steel wire of various lengths, stored on comparatively weighty metal spools dating from 1890s through 1960s. The Society has also preserved antiquated and obsolete playback equipment dating from statehood through present day. AWebster-Chicago Electronic Memory recorder lay dormant, vacant of life, and entombed within the audiovisual vault, conserved for those future archival archaeologists to explore.

This Webster-Chicago Electronic Memory Recorder, respectfully named,"Big Bertha Webster," weighs approximately 37 pounds without individual recordings attached. She is accompanied by a sturdy microphone approximately the size of a child's hand with heavy metal designer casing attached to 'Bertha' by a peculiar three-pin Cinch Jones connector.

'Bertha' was removed from her ossuary and purposely examined. Each knob, switch, button, and mechanism was seemingly carefully designed to reflect the purpose both aesthetically and culturally current in time.The beauty of Bertha stopped patrons and staff in their tracks as they walked past the Digitization Studio. But Bertha also came with complexities and challenges. Archivist predecessors long retired and a machine manufactured in the late 1930s posed the vexing and arduous task of resurrecting Bertha in order to explore our past.

Vigorously combing storage, collection repositories, and placing a 'call out' for donations of operational or non-operational wire recorder machines, two additional pieces arrived none too soon. The short lived lifespan of these fascinating wire machines stirred intrigue but also presented the challenge of gathering resources through virtual environment, enthusiasts, and elders who had first hand awareness.

The Digitization Studio slowly transformed into a laboratory of mad science. Bertha, now laid out, disemboweled, and poised for autopsy, was accompanied by her new companions. Electronic schematics, highlighted, starred, and strewn about, clearly extended a sense of inventive re-discovery. Pieces were laboriously cleaned, oiled, and repaired from each specimen. Each fuse, lamp, and guide was tested for vitality. A two-pin Jones plug was ordered from an audio enthusiast found online and wired into Bertha, then patched into the jackfield for digitization (see more detailed descriptions at Journey of Big Bertha Webster ${ }^{133}$ ). Each mechanism then found its place within Bertha's body to provide the essential breath of life.

Turning the 'Tone' switch in a clockwise direction caused Bertha to stir; a low humming accompanied a slight glimmer of light which struggled to illuminate the clear glass bulb that signified the machine was 'on'. Peering into the machine, one could see mechanisms, gears, and wires firing. It was time to test the playback module. An unmarked metal spool of steel wire was selected and placed on the uptake left wheel. A larger metal wheel was situated on the right to catch and wind played wire. Between the two playback wheels was a spool that rose and fell in a smooth repetitious beat to guide the wire evenly from one to the other. Bertha began

133 http://www.japryse.com/\#!journey-of-big-bertha-webster-the-wire/trm9a. 
to sing, a rather humorous magnetized recording of a young girl and her family recording in their home (Lyrics from Oklahoma! written by composer Richard Rodgers and lyricist/librettist Oscar Hammerstein II):

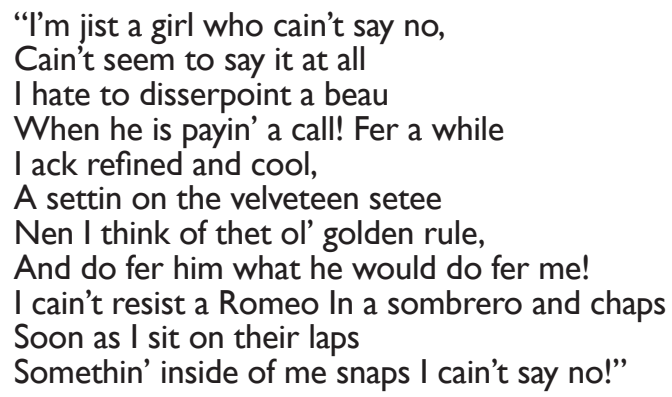

With a laugh and a joke, a man chimes in and we are transported to a moment in time where family is heard entering and exiting a wooden screen door that snaps and slams with each movement. We learn of war, boyfriends, baseball segregation (male and female), and school. Jokes were made about Hugo ("who go?") Oklahoma, and a "guy named Who Asked You" (Hugh Askew-who truly existed circa 1940). We hear from a father, mother, sisters, and an uncle, all sitting around this then state-of-the-art magnetic wire machine creating a lifeline into the 1940s. It is as if the lemonade served is fresh and the sun was shining. The birds in the background are singing and for an instant, frozen in time, it was though you were a part of their lives.

Illuminating the mystery of Bertha has unlocked priceless moments of historical treasure well on its way to degradation and decay, soon lost and forgotten. Recordings of specific dialect, tones, and cadence that accompany phrases of cultural significance in that particular era provides a sense of societal materialization which contributes to the analysis of present day languages.

The Oklahoma Historical Society, Digitization Division, continues to be a forerunner in modern research capability through continuous examination of anachronistic aspects of time. Exploring cultural heritage requires the exploration of all types of recorded sound from wax cylinders to vinyl recordings, magnetic wire to magnetic tape. Without uncovering these abilities through education, practice, and community efforts, and accommodating each mode and format, the institution of historical transference fails. Selective convenience of available playback equipment and limited preservation processes relegates moments in time inequitably which leads to incomplete historical experiences. As archival archaeologists it is imperative to explore and develop processes which coincide with institutional vision and to explore the cultural material accessed in order to convey factual interpretations which attaches meaning and clarification of actions from our past. ${ }^{134}$

I34 For more information concerning wire recordings and their history, see: http://cultureandcommunication.org/ deadmedia/index.php/Wire Recording\#Historical precursors and futuristic musings. 